\title{
Empirical research in business process management: introduction to the special issue
}

\author{
Jan Recker • Bela Mutschler • Roel Wieringa
}

Published online: 14 August 2010

(C) Springer-Verlag 2010

\section{Introduction}

In this editorial letter, we provide the readers of Information Systems and e-Business Management with an introduction to Business Process Management and the challenges of empirical research in this field. We then briefly describe selected examples of current research efforts in this field and how the papers accepted for this special issue contribute to extending our body of knowledge.

\section{Business process management and the empirical research challenge}

The improvement of business processes is a perennial top priority of chief information executives (Gartner Group: Leading in Times of Transition 2010). When seeking to re-design business processes to improve operational efficiency, increase compliance or foster business innovation, managers increasingly turn to Business Process Management (BPM) (Smith and Fingar 2003). The attraction of BPM lies in its promise to create sustainable high-performing processes that demonstrate strategic strengths such as the ability to respond better to rapid change or to standardise operational best practice practices across business units or locations.

J. Recker $(\bowtie)$

Queensland University of Technology, Brisbane, Australia

e-mail: j.recker@qut.edu.au

B. Mutschler

University of Applied Sciences Ravensburg-Weingarten, Weingarten, Germany

e-mail: bela.mutschler@hs-weingarten.de

R. Wieringa

University of Twente, Enschede, The Netherlands

e-mail: R.J.Wieringa@ewi.utwente.nl 
Providing effective IT support for business process management has become a key enabler for process-oriented organizations. In response to this need, numerous process support paradigms such as workflow management (van der Aalst and Van Hee 2004) or case handling (van der Aalst and Weske 2005), process specification standards such as WS-BPEL (Andrews et al. 2003) or BPMN (OMG 2009), process tools such as ARIS (Scheer 1994), YAWL (van der Aalst and ter Hofstede 2005) or ARISTAflow (Dadam et al. 2009), and process methods, such as process modelling (Recker et al. 2009), process analysis (Phalp and Shepperd 2000), or process redesign (Reijers and Mansar 2005), have emerged in recent years. These paradigms, standards, tools, and methods have become success-critical instruments for improving process performance.

Information Systems research in the area of BPM has traditionally focused on the development and extension of associated tools, methods, standards and technologies. However, when evaluating the suitability of existing BPM technology for a particular project, it is important for practitioners and academics alike to have an informed opinion about their qualities and deficiencies. In particular, the demand for insights or evaluations of BPM technology based on empirical research has largely been neglected so far, with contributions on BPM technology (Weber et al. 2010) or method (Recker et al. 2011) evaluation emerging only recently. With this special issue, we sought to further grow this emerging body of knowledge, and extended an invitation to researchers to adopt empirical research in the area of BPM, in order to achieve benefits similar to those demonstrated in areas like software engineering (e.g., in the context of software development processes or code reviews), information systems, or management science.

From the introduction of empirical research methods such as experimental, survey or case study methods into BPM (as well as into the development of processaware information systems), we expect more valid, quantitative or qualitative data on the various aspects and effects of BPM technology. This becomes important, not only for IT professionals, but also for researchers dealing with analytical, theoretical or technical challenges in the field of BPM.

The ER-BPM'09 workshop picked up this demand and sought to stimulate empirical research that, in turn, can contribute to a better understanding of the problems, challenges and existing solutions in the BPM field. In particular, the workshop provided an interdisciplinary forum for both researchers and practitioners to improve the understanding of BPM-specific requirements, methods and theories, tools and techniques. Eight paper presentations, two prototype tool demonstrations and one keynote were given at the workshop to around forty participants from all around the world. Forthcoming from this workshop, this special issue was incepted to provide an interesting selection of insights provided by current empirical research in the field of BPM.

\section{Contents of the special issue}

This special issue is closely related to the 1st International Workshop on Empirical Research on Business Process Management (ER-BPM), which was organized by the 
special issue editors in conjunction with the International Conference on Business Process Management 2009 in Ulm, Germany. The special issue combined an open call for papers with a number of paper invitations selected from the eight full paper and two tool presentations at ER-BPM 2009. In response to the call for papers for this special issue, thirteen submissions were received. After three rounds of review, we selected the following four papers for inclusion in the special issue.

The first paper, "Six Sigma as a Business Process Management Method in Services-Analysis of the Key Application Problems", by Florian Johannsen, Susanne Leist and Gregor Zellner, takes a look at the application of Six Sigma as a BPM method. Apart from being applied in production, Six Sigma has lately gained considerably attention as a BPM method in service industries. The transfer of the method from production to service applications does, however, pose problems that affect successful implementations. Knowing and understanding these problems is helpful in order to be able to avoid them and to achieve the goals of Six Sigma improvement projects. The paper by Johannsen et. al picks up this challenge by analyzing existing literature on this subject in a first step. As a second step, a survey based on the problems found in the literature is conducted to compare theory and practice. The evaluation of the results shows, on the one hand, that, to date, the problems of the application of Six Sigma in services have not sufficiently been dealt with. On the other hand, the evaluation provides a survey of the problems structured in accordance to the phases of the Six Sigma cycle. Altogether, the presented paper offers interesting findings going well beyond the known state-of-the-art of the Six Sigma method.

The second paper, "The Joint Impact of Service-oriented Architectures and Business Process Management on Business Process Quality: An Empirical Evaluation and Comparison" by Daniel Beimborn and Nils Joachim, deals with the question how high business process quality can be achieved through the interplay between BPM and SOA. Specifically, the authors empirically investigate the impact of both SOA and BPM on business process quality in terms of straightthrough processing, business-to-business integration, quality control, as well as standardization and consolidation of business processes. The empirical study is based on data from 157 German service firms. Results show that the SOA paradigm has still received rather low adoption rates in the industry. However, the study also shows that SOA, BPM, and related information technologies have a direct positive impact on business process quality and the analysis provides evidence for the complementarities of BPM and SOA since interaction effects between them have an additional significant impact on business process quality.

In the third paper, "Uncovering ITIL Claims: IT Executives' Perception on Benefits and Business-IT Alignment", Mauricio Marrone and Lutz Kolbe report on an international survey of 441 firms about the benefits that the IT Infrastructure Library (ITIL), the de-facto best practice framework for IT Service Management processes, provided to the IT organizations. Their study examines operational as well as strategic characteristics of the firms participating in the survey, and focuses on the relationship between business-IT alignment maturity and the adoption of the ITIL best practice processes. The study shows that the adoption of ITIL processes 
positively contributes to operational benefit realization as well as to business-IT alignment maturity.

The fourth paper, "Advances in Business Process Management Implementation based on a Maturity Assessment and Best Practice Exchange" by Michael Rohloff, reports on a case study on the implementation of Business Process Management in a large international company. In this case study, the author focuses on the development of reference frameworks and maturity assessment models to guide the implementation process. The results are of interest to audiences interesting in the adoption of Business Process Management in large organizational cohorts.

In summation, we believe this collection of papers not only makes an interesting read but is also representative of the current global research efforts in the Business Process Management field. While the papers differ in the specific emphasis they place, we believe that they can serve as an inspiration for other researchers to contribute to building an innovative and empirically grounded body of knowledge that delivers insights to organizations that strive for business innovation, operational excellence and agility. We trust you will enjoy reading this special issue.

\section{References}

Andrews T, Curbera F, Dholakia H, Goland Y, Klein J, Leymann F, Liu K, Roller D, Smith D, Thatte S, Trickovic I, Weerawarana S (2003) Business process execution language for web services. Version 1.1. BEA Systems, International Business Machines Corporation, Microsoft Corporation, SAP AG and Siebel Systems, available at: http://xml.coverpages.org/BPELv11-May052003Final.pdf

Dadam P, Reichert M, Rinderle-Ma S, Goeser K, Kreher U, Jurisch M (2009) Von ADEPT zur AristaFlow BPM Suite - Eine Vision wird Realität: "Correctness by Construction" und flexible, robuste Ausführung von Unternehmensprozessen. EMISA Forum 29:9-28

Gartner Group: Leading in Times of Transition (2010) The 2010 CIO agenda. EXP premier report January2010. Gartner, Inc, Stamford, Connecticut

OMG (2009) Business process modeling notation, V2.0. Object management group, available at: http://www.omg.org/spec/BPMN/2.0

Phalp KT, Shepperd M (2000) Quantitative analysis of static models of processes. J Syst Softw 52:105-112

Recker J, Rosemann M, Indulska M, Green P (2009) Business process modeling: a comparative analysis. J Assoc Inf Syst 10:333-363

Recker J, Rosemann M, Green P, Indulska M (2011) Do ontological deficiencies in modeling grammars matter? MIS Quarterly 35 (in press)

Reijers HA, Mansar SL (2005) Best practices in business process redesign: an overview and qualitative evaluation of successful redesign heuristics. Omega 33:283-306

Scheer A-W (1994) ARIS toolset: a software product is born. Inf Syst 19:607-624

Smith H, Fingar P (2003) Business process management-The third wave. Meghan-Kiffer Press, Tampa, Florida

van der Aalst WMP, ter Hofstede AHM (2005) YAWL: Yet Another Workflow Language. Inf Syst 30:245-275

van der Aalst WMP, Van Hee K (2004) Workflow management: models, methods and systems. MIT Press, Cambridge, Massachusetts

van der Aalst WMP, Weske M (2005) Case handling: a new paradigm for business process support. Data Knowl Eng 53:129-162

Weber B, Mutschler B, Reichert M (2010) Investigating the effect of using BPM technology: results from a controlled experiment. Sci Comput Program 75:292-310 